\title{
Conducting Postgraduate Level Research: Selecting A Methodology- A Students' Perspective
}

\author{
Vlasios Sarantinos \\ Department of HRM, University of Strathclyde, UK \\ E-mail: vlasios.sarantinos@gmail.com
}

\begin{abstract}
In the vast majority of postgraduate research, an integral part of business students is to select an appropriate methodology to suit the particular research needs of each project. In this paper we present issues, problems and real-time practical issues from the perspective of a young researcher. Through a specific subject matter and two exemplary methodologies we present a concise review of the methodological dimensions to come up with an optimal solution that will maximize the potential of the project.
\end{abstract}

Keywords: Research project, Psychological contract, Methodology

\section{Introduction}

Undeniably, one of the most critical part of any postgraduate piece of work is the ability to select the methodology appropriate to the subject matter that will enable the researcher to develop the project adequately enough with the novel elements required to differentiate it from the existing pieces of work. In this paper we present an example of how a student can contemplate two research methods for a specific topic, not from a textbook perspective but from the framework of a student already in the actual making of his research project. Initially, we introduce the importance of selecting an appropriate methodology using a default subject matter from the area of human resources management. Continuing, we consider two potential methodologies survey type research and case-study creation for the particular research context, concisely discussing the pros and cons of each in terms of research philosophy, practicalities in research and inherent limitations.

\section{Choosing an appropriate methodology: Kicking of from the relevant literature}

An integral part in any critical piece of work is the methods used to formulate, substantiate and comment on the arguments usually found in the literature or conjectured at the beginning of the project. Depending on the project type, philosophy, scope and numerous other factors, the methodology adopted for data collection can take different forms and the researcher can use several different instruments dependent on the initial parameters decided on the outset of the project. The problem under scrutiny for our research area refers to the psychological contract and the element of trust in the employment relationship.

In particular we are trying to recognize the connections between employees and supervisors from the top levels of the hierarchy to line managers and common employees within the social healthcare section. Additionally, we are attempting to examine the line of intervention of top-level management to the every-day affairs between line managers and employees in terms of interest, practicality and capability of intervention. The psychological contract firstly coined by Argyris in 1960 has been thoroughly researched and argued. The various arguments in the field include questions about its nature, whether the term 'contract' is accurate or not especially when compared with written contracts (Arnold, 1996) whilst others attributed to this type of unwritten agreements significant enough powers to resemble in terms of validity and influence a standardised written contracts (Sparrow and Marchington, 1998; Deery, Iverson and Walsh, 2006).

Psychological contracts have been often defined according to their particular characteristics. For example, Rousseau (1995 and 2000) distinguishes between two types of PC:

- transactional contracts, which are structured with emphasis on material rewards that have a short-term duration and are relatively narrow in their scope; and

- relational contracts, which are structured around less tangible rewards, have a significant duration (often without an implied end-date) and are subject to the individual parties' beliefs.

Another interpretation of the PC was offered by Guest and Conway (1997, 1998 and 2004) representing overall the CIPD mentality on the PC (CIPD 2003, 2004 and 2005a). Whilst other researchers (Sparrow and Marchington, 1998; Rousseau, 1998) view the PC as an analytical tool to grasp the complex changes that occur throughout the organization when new employment practices are adopted, Guest and Conway (1998) view the PC as a means to understand the state 
of the employment relationship in an organization and for plotting corresponding changes. In terms of the various methodologies used, we can see a significant preference to questionnaire and interview type research (Robinson; 1996; Guest \& Conway, 2000; 2002)

\section{Considering the methodology}

On considering how to approach the subject matter, the most appropriate methodologies cannot skew significantly from the general trend towards questionnaires and interview-based methods. There are several reasons advocating the use of such instruments pertaining both to the inherent research philosophy and to practical considerations when conducting the data collection and analysis. On the other end, we shall examine the potential use of case-study creation as an alternative method. Considering each method individually, surveys are driven primarily by a positivistic paradigm,(Popper, 2002;2004) aiming to examine usually a set of predetermined hypotheses in a particular setting as is the case with our particular research question (Smith et. al 2002). The hypothetico -deductive framework also offers some important elements that fit the selected organizational setting to carry out the research.

Initially, the research question will be tested on a standardised organizational setting most likely a hospital where the researcher might be given access to conduct research but it is doubtful that he will have much or any capacity to actually becoming involved in the setting further from dispensing some questionnaires or carrying out some interviews. Consequently, the researcher needs to consider the overall research process as an objective reality in order to maximize the aims set at the outset. Given the conditions for operating in the specific research environment, a linear hypothetico-deductive method of testing a series of pre-determined questions appears quite suitable. As such, it is important for the research to adhere to the basic perception of objectivity in reality and the same should follow for the knowledge that is generated in the research process (Creswell, 1994).

Equally as we have already mentioned, survey type research is driven primarily be a positivistic stance emphasing in particular the quantitative strength in data collection and especially in the analysis stage with a linear principle at the forefront. As our research question contains specific variables we hypothesise about and which we seek to test in the healthcare section, the linearity in terms of methodology both in terms of philosophy and in terms of implementation further from applicable to the requirements of the organizational setting, it also operational in the actual facilitation of the research.

Essentially, this methodology offers a straightforward, adequate and practical manner in conducting our research. Straightforward as it allows to the researcher to immediately begin formulating the instruments for data collection firstly because the research environment is more adaptable in such an approach and secondly because the nature of the research question structure can be converted directly into a methodology (Buckingham \& Saunders, 2004). The latter is also evident through the previous research carried out in the field as we mentioned earlier, survey type research holds the preference of the most endeavours in the literature.

The alternative methodological approach we shall consider is case study creation for the purposes of our specific research question. In principle, case-studies usually examine more in-depth, at times over a longitudinal fashion of a smaller 'sample' or instance as termed by the word case to both generate and test hypotheses (Yin, 1993, 1994; Flyvbjerg, 2006). In the later sense, case-study can also fit with the prerequisite of our research question and the pre-determined questions we wish to examine. Due to its in-depth nature, contrasting to survey type research case-studies fall more into the qualitative spectrum rather than producing quantitative results without omitting the instance of co-existence (Yin, 1994).

In regards to data collection, typical instruments could include events such as interviews, archival records, participatory observation etc. For example, the interviews as we mentioned previously when considering the survey type research can also be used if a case-study method was adopted. The issue concerning the particular research question though is the size of the sample since there might be a difference in the context as survey-based interviews apart from the context also require a significantly larger sample than we would expect to find in a case-study as the objective is to obtain statistical information rather than qualitative texture.

The latter difference also pertains to the emphasis given in the research design and what is our primary objective in the data collection stage. If the interest is focused in obtaining sufficient enough sample for statistical substantiation then it is vital to obtain a significantly adequate sample of either questionnaire responses or interviewees or both. On the other end, if we are interested mainly on eliciting more in-depth information and delving perhaps deeper in the argumentology, than the case-study option might be more appropriate.

An additional factor we have to take into account are the practicalities when conducting the research and namely the various constraints that are bound to exist. For one, in our particular research environment we have constraints imposed by the organisation in terms of access and time. For example if we select the survey-type approach it is necessary to obtain permission first to conduct the research in the hospital and then to ensure we will have enough feedback. Equally, for the case-study option access to formulate the components of the case-study is required and secondly the information 
that will be collected must not impinge on any data-protection agreement or legal stipulation in order to be granted access to carry out the research. Similarly the are issues of time and scope that are inherent to any project so as not to be carried away and end up with a too small or to large sample for the purposes of the specific project and the relevant objectives.

Naturally, the pragmatics exist in any line of research as are the difficulties that arise from them. In order to surpass them, needs to be careful planning from the very start of the project. When drawing the research question and then onwards to formulating the research, design it is essential to carefully decide upon the research methodology that best fits the question, will provide the most optimal input for the analysis stage and at the same time minimises the practical obstacles. Essentially, at this stage we need to calculate all the parameters, taking into account the nature of the research question and of each method available, compare them against each other or in combination and adapt either our research question in a manner that does not compromise the objectives of the project or tweaking the methods' parameters to fit our research or even both. It is essential to point out that this is an ongoing process and most likely there will be several instances during every stage of the research that there will some level of review and potential change in the design, implementation and analysis phases of the examination and but this is an unavoidable and vital element to produce a novel, rigorous and in-depth outcome.

\section{Conclusions}

Selecting an appropriate methodology is a vital part for any postgraduate level research, from a simple thesis to a research paper in order to add the elements that will differentiate this piece of work from the previous tasks carried out in the field. The researcher needs to carefully weigh from the very early stages of the project all the information, the research question, the particulars of the methodologies available, the relevant philosophy, practical issues such as access, time and various other expected constraints coming finally down with an overall research mix that will allow to the student to progress and grow along with project raising both the academic merit of the project and individuals' own skills.

\section{References}

Argyris C. (1960). " Understanding organizational behaviour", Homewood, IL: Dorsey.

Arnold, J. (1996). 'The psychological contract: A concept in need for closer scrutiny?', Research Series Paper No. 17, Loughborough: Loughborough University Business School.

Buckingham, A \& Saunders, P (2004). " The survey methods workbook", Polity.

Creswell, J. W (1994). " Research design- Qualitative and quantitave approaches London: Sage.

Deery, S. J., Iverson, R. D., and Walsh, J. (2006) ' Towards a better understanding of psychological contract violation: A study of customer service employees', Journal of Applied Psychology, 91 (1), pp. 166-175.

Easterby-Smith, M., Thorpe, R. \& Lowe, A. 2002. “Management Research: An Introduction" (2 ${ }^{\text {nd }}$ ed.). London: Sage Publications.

Flyvbjerg B. (2006). “Five Misunderstandings About Case Study Research" Qualitative Inquiry, vol. 12, no. 2, pp. 219-245.

Guest D. and Conway N. (1997). 'Employee motivation and the psychological contract', Issues in People Management No. 21. Wimbledon: IPD.

Guest E. D \& Conway, N. (2000). " The psychological contract in the public sector" Research Paper, London: CIPD publishing.

Guest E. D. and Conway N. (2002). 'Communicating the psychological contract: an employer perspective', Human Resource Management Journal, 12 (2), pp. 22-38.

Guest E. D. and Conway, N. (2004). Employee well-being and the psychological contract, London, CIPD.

Guest, D., and Conway, N. (1998). Fairness at work and the psychological contract, London: IPD.

Popper, K.R. (2004). "The Logic of Scientific Discovery" ( $2^{\text {nd }}$ ed.). London: Routledge.

Popper, K.R. 2002. "Unended Quest: An Intellectual Autobiography". (5 $\left.5^{\text {th }} \mathrm{ed}\right)$ London: Routledge.

Robinson, S. 91996). "Trust and breach of the psychological contract" Administrative Science Quarterly. V. 41, No. 4: pp 574-599.

Rousseau, D. M. (1995). Psychological Contracts in organisations: Understanding written and unwritten agreements, Newbury Park, CA: Sage.

Rousseau, D. M. (1995). Psychological Contracts in organisations: Understanding written and unwritten agreements, Newbury Park, CA: Sage. 
Rousseau, D. M. (1998). 'The `problem` of psychological contract considered', Journal of Organizational Behaviour, 19, pp. 665-671.

Rousseau, D. M. (1998). 'The 'problem` of psychological contract considered', Journal of Organizational Behaviour, 19, pp. 665-671.

Rousseau, D. M. (2000). Psychological Contract Inventory: Technical Report, Heinz School of Public Policy and Graduate Industrial Administration, Carnegie MellonUniversity. http://www.andrew.cmu.edu/user/rousseau/0_reports/PCI.pdf retrieved 28/01/2008.

Rousseau, D. M. (2000). Psychological Contract Inventory: Technical Report, Heinz School of Public Policy and Graduate Industrial Administration, Carnegie Mellon http://www.andrew.cmu.edu/user/rousseau/0_reports/PCI.pdf retrieved 28/01/2008.

Yin, R. K. (1993). “ Applications for case study research” Newbury Park. CA: Sage.

Yin. R. K. (1994). “ Case study research: Design and Methods” ( $2^{\text {nd }}$ ed): Thousand Oaks: Sage. 